\title{
MICROMARCAS ONDULADAS EM SEDIMENTOS PALEOZÓICOS DA BACIA DO PARNAÍBA E DA REGIÃO DO GURUPI (NE DO ESTADO DO PARÁ)
}

\author{
WERNER TRUCKENBRODT*
}

\begin{abstract}
Two types of small-scale ripple-like surface features are described from fine-grained sediments: (i) wrinkle marks from the Pimenteiras, Piriá and Pedra de Fogo Formations, and (ii) millimetre ripples from the Longá Formation. All these sediments belong to the Parnaíba Basin with exception of those of the Piriá Formation. These minute sedimentary structures are considered to be good indicators of intermittent emergence or quasi-emergence of a sedment surface (Reineck \& Singh 1980). Structures very similar to wrinkle marks are know such as foam marks, disfigured raindrop imprints and modified adhesion ripples, which are indicative, like the wrinkle marks, of emergence surfaces and patterns of wrinkles and ridges originated in deep-water flysch sediments. Available data from the literature show that wrinkle marks and milimetre ripples have been most frequently recorded from tidal flat environments. Other shallow water environments like shoals, lake coasts, playas etc. seem to be less favorable for the formation and preservation of these structures. The Paleozoic sediments of the Parnaiba Basin, from which the ripple-like surface features were collected, were deposited in shallow marine conditions, probably in tide demoninated environments. According to Mabesoone (1977) the Pimenteiras Formation represents the purest features of the tidal flat and channel facies. It seems that at least a part of the Lower Paleozoic Piriá sediments of the Gurupi region was also deposited in the intertidal environment.
\end{abstract}

INTRODUÇÃo As marcas onduladas têm sempre chamado a atenção de sedimentólogos e por isso têm sido objeto de muitos estudos visando desvendar a dinâmica de sua formação e a implicação ambiental de seus vários tipos (Allen 1968, Harms et al. 1982, Reineck \& Singh 1980, Sarkar 1981, Tanner 1967). Estruturas semelhantes às marcas onduladas, mas em escala menor e de aspecto pouco saliente, são as feições de micromarcas onduladas com comprimento de onda de poucos milímetros. Estas marcas, pouco divulgadas em textos didáticos especializados, são conhecidas de ambientes deposicionais de água rasa, sobretudo de planície de maré.

No presente trabalho são descritos quatro exemplos de micromarcas onduladas oriundas de sedimentos paleozói$\cos$ da Bacia do Parnaíba e da região do Gurupi/NE do Estado do Pará (Província Parnaíba seg. Hasui et al. 1984) com o objetivo de: a) mostrar sua importância na interpretação do ambiente deposicional em geral, com base, principalmente, nos registros bibliográficos disponiveis sobre as micromarcas onduladas e os paleoambientes correspondentes, e b) analisar seu papel nos sedimentos paleozóicos da referida província.

\section{ASPECTOS GEOLÓGICOS E DESCRIÇÃO DAS MICRO- MARCAS ONDULADAS Na Bacia do Parnaíba foram} encontradas micromarcas onduladas em siltitos das Formações Pimenteiras (Devoniano Médio a Superior) e Longá (Devoniano Superior e Carbonífero Inferior), como também em arenitos muitos finos, atribuídos, com certa reserva, à Formação Pedra de Fogo (Permiano Inferior a Médio). Estes últimos talvez pertençam à Formação Motuca (Perimiano Superior), o que não pôde ser esclarecido com certeza. As micromarcas onduladas observadas na região do Gurupi ocorrem num arenito fino da Formação Piriá (Paleozói- co Inferior).

Os afloramentos de micromarcas, denominados P-1 a P-4, estão localizados na Figura 1.

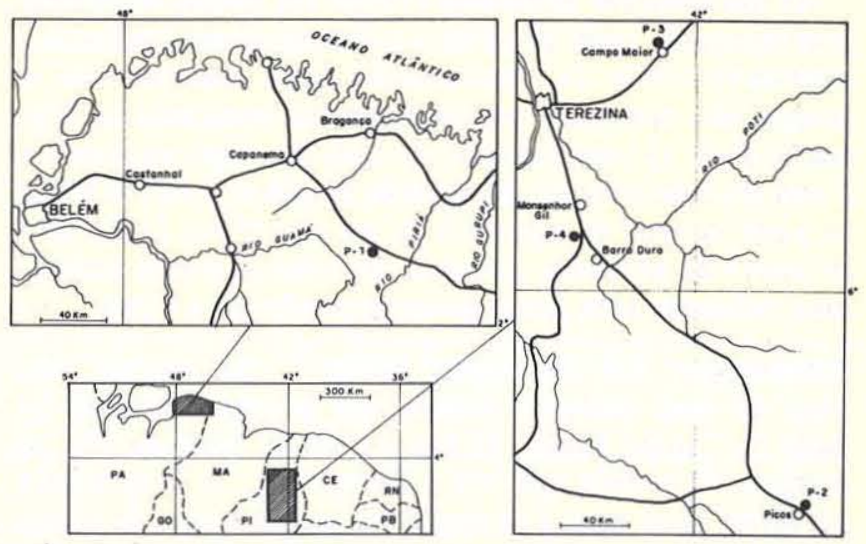

Figura 1 - Localizaçāo dos afloramentos P-1 a P-4 com micromarcas onduladas (small-scale ripple-like surface features) P-1: Formação Piriá; P-2 Formação Pimenteiras; P-3: Formação Longá; P-4: Formação Pedra de Fogo (?)

Afloramento P-1 Formação Piriá Trata-se de um corte de estrada situado no $\mathrm{km} 219$ da rodovia BR-316, cerca de $65 \mathrm{~km}$ a SE da cidade de Capanema (Fig. 1). A sequêencia ali exposta, mergulhando em média $20^{\circ}$ para NW, é constituída predominantemente de siltitos intercalados com arenitos finos a grosseiros, muito intemperizados. A cor dos sedimentos varia entre amarelada, vermelho amarronzado e arroxeada. Diminutas manchas brancas em arenitos indicam a presença original de grãos de feldspato. Preva- 
lece a estratificação plano-paralela nestes sedimentos, embora algumas camadas apresentem superfície onduladas.

As micromarcas onduladas foram encontradas na parte superior do afloramento P-1, na superfície de uma camada de arenito fino, compacto, de cor amarelada, cortado por vênulas de quartzo. $\mathrm{O}$ padrão apresenta um sistema de rugas interligadas com aspecto reticular (Foto 1). Cristas e calhas são aproximadamente eqüidimensionais, com comprimento de onda de 3 a $5 \mathrm{~mm}$. A altura das rugas está em torno de 1 $\mathrm{mm}$. Embora as micromarcas onduladas encontrem-se parcialmente destruídas, nota-se que elas têm uma distribuição original limitada com respeito à sua extensão na superfìcie da camada do arenito.

Afloramento P-2 Formação Pimenteiras Essa ocorrência está localizada na cidade de Picos (PI) (Fig. 1), num morrote situado ao lado do cemitério. Nos flancos dessa saliência estão expostos folhelhos e siltitos, intercalados subordinadamente com arenitos que, no topo do afloramento, formam um paredão com aproximadamente $4 \mathrm{~m}$ de altura. Os arenitos apresentam vários tipos de estratificação cruzada, além de exibirem laminação plana.

As micromarcas onduladas foram encontradas no topo de uma pequena placa solta de siltito oriunda da parte inferior da seqüência. $\mathrm{O}$ siltito, de cor vermelho amarronzado, apresenta laminação plana pouco desenvolvida. Sob o microscópio ele revela, além do quartzo, grãos de feldspato, lamelas bem orientadas de mica e óxido de ferro.

As micromarcas onduladas exibem um padrão levemente anastomosado, onde as cristas e calhas mostram tendência à orientação (Foto 2), contrastando desta maneira com o arranjo não orientado das micromarcas onduladas da Formação Piriá. $\mathrm{O}$ comprimento de onda das rugas varia de 1 a $2 \mathrm{~mm}$ no lado inferior, à esquerda da placa, e de 2 a $3 \mathrm{~mm}$ na parte restante da superfície da amostra (Foto 2). Quanto ao relevo da estrutura, as cristas são mais ou menos simétricas e redondas, com altura geralmente inferior a $1 \mathrm{~mm}$.

\section{Afloramento P-3 Formação Longá Ás marcas pro-} vêm de uma pedreira situada nas proximidados da cidade de Campo Maior, $85 \mathrm{~km}$ a ENE de Teresina (PI), na margem da estrada que leva a Barras (Fig. 1). E explorada há vários anos para a obtenção de placas e lajes de siltito, utilizadas para revestimentos, cercas etc. O principal tipo litológico encontrado no afloramento é um siltito de cor cinza, mostrando estratificação plano-paralela até levemente ondulada. Ocorrem também arenitos finos, freqüentemente em forma de lentes, exibindo microestratificação cruzada. Além das micromarcas onduladas foram observadas marcas onduladas de interferência e vários tipos de fósseis traços (Muniz 1982).

As micromarcas onduladas coletadas (Foto 3) cobrem a superfície de duas placas de siltito, de cor cinza-claro, que apresentam uma laminação interna plano-paralela. Observam-se ainda, nestas amostras, pequenas lentes de arenito muito fino, composto, como o siltito, de quartzo, minerais argilosos, sericita e feldspato.

As micromarcas são caracterizadas por cristas e calhas eqüidimensionais, retilíneas e paralelas. As cristas aparecem achatadas com um relevo pouco pronunciado. O comprimento de onda é de aproximadamente $5 \mathrm{~mm}$ e não apresen. ta variações significativas.
Afloramento P-4 Formação Pedra de Fogo A ocorrência situa-se em arenitos mal expostos num pequeno corte à margem da rodovia $\mathrm{BR}-316,74 \mathrm{~km}$ a S de Teresina. Fica próximo ao lugar chamado Alto Novo, entre as localidades de Monsenhor Gil e Barro Duro (Fig. 1). Os arenitos, de cor vermelha, marrom ou amarelo esbranquiçado, possuem granulometria fina e formam camadas, em geral levemente onduladas, de espessura centimétrica, que exibem laminação cruzada.

Como já foi assinalado, a posição estratigráfica desses sedimentos é incerta, não tendo sido estabelecido se pertencem à Formação Pedra de Fogo ou à Formação Motuca.

As micromarcas onduladas foram encontradas juntamente com marcas onduladas simétricas no topo de uma placa solta de um arenito de granulação fina, embora em níveis algo diferentes, como mostra a Foto 4 . Na base da placa ocorrem fragmentos achatados de argila (mud chips) de dimensões milimétricas e centimétricas. A composição mineralógica deste arenito caracteriza-se por quartzo, óxido de ferro e poucos grãos de feldspato.

As micromarcas onduladas desse afloramento são semelhantes às dos sedimentos da Formação Piriá. Ocorrem, como nesta última, apenas localmente no topo de uma camada de arenito, apresentando um arranjo em forma de favo e um comprimento de onda variando de 4 a $5 \mathrm{~mm}$.

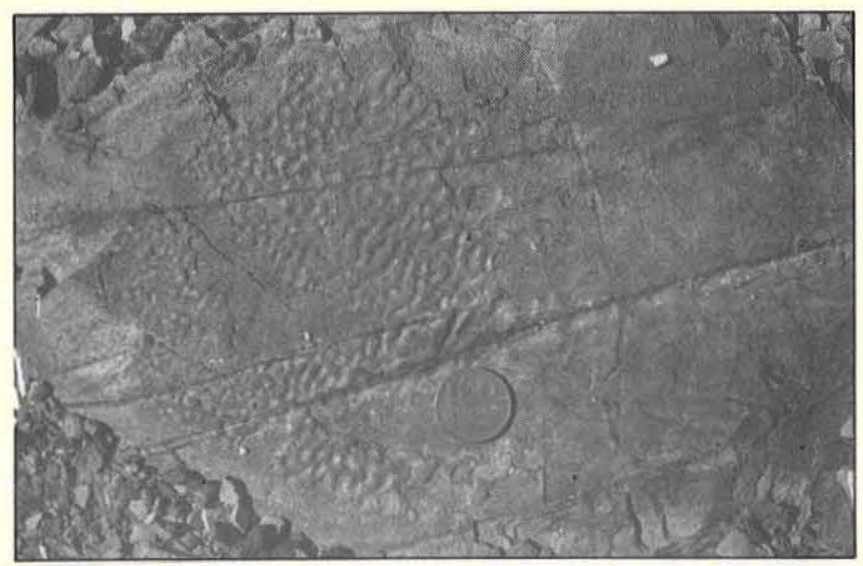

Foto 1 - Marcas rugosas (wrinkle marks) na superficie de um arenito fino, Formação Piriá. Corte de estrada, $\mathrm{km} 219$ da rodovia $B R-316$

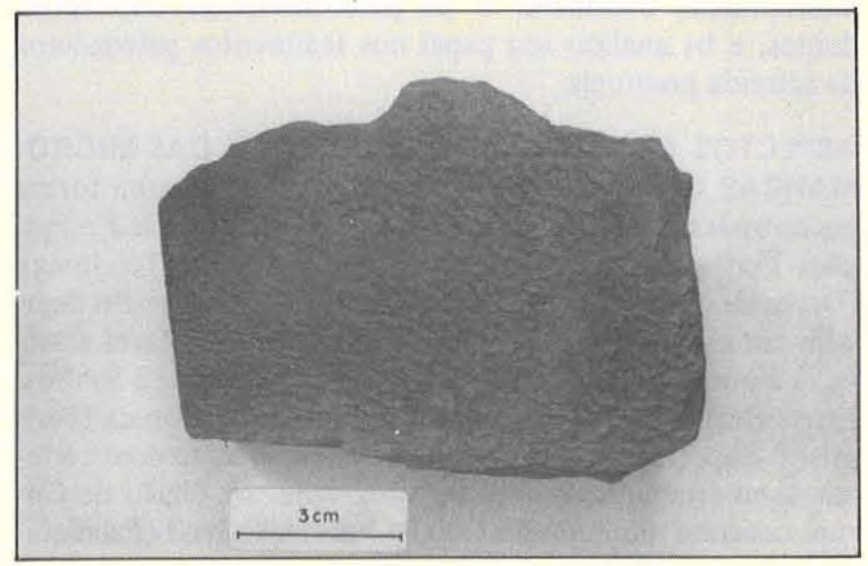

Foto 2 - Marcas rugosas (wrinkle marks) no topo de uma placa de siltito. Formação Pimenteiras. Picos, morrote ao lado do cemitério 


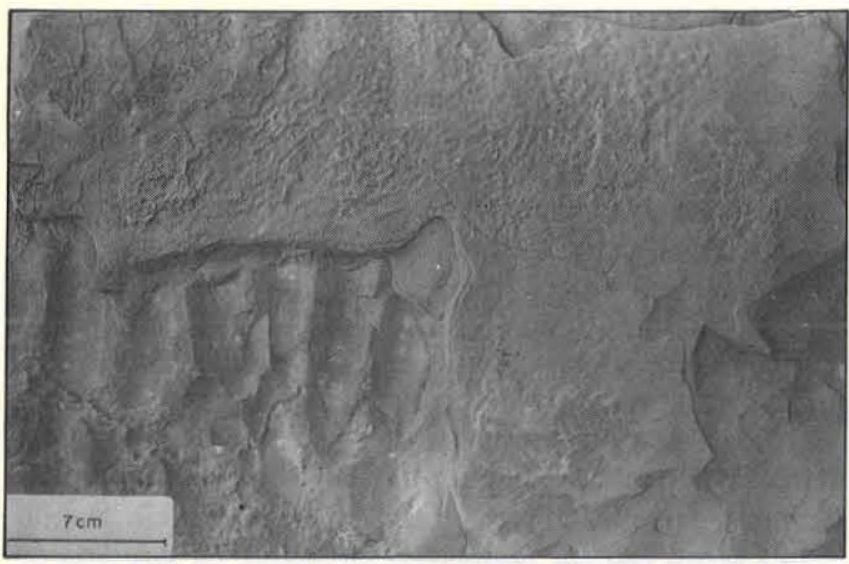

Foto 3 - Ôndulas milimétricas (millimetre ripples) no topo de uma placa de siltito, Formação Longá. Pedreira nas proximidades de Campo Maior.

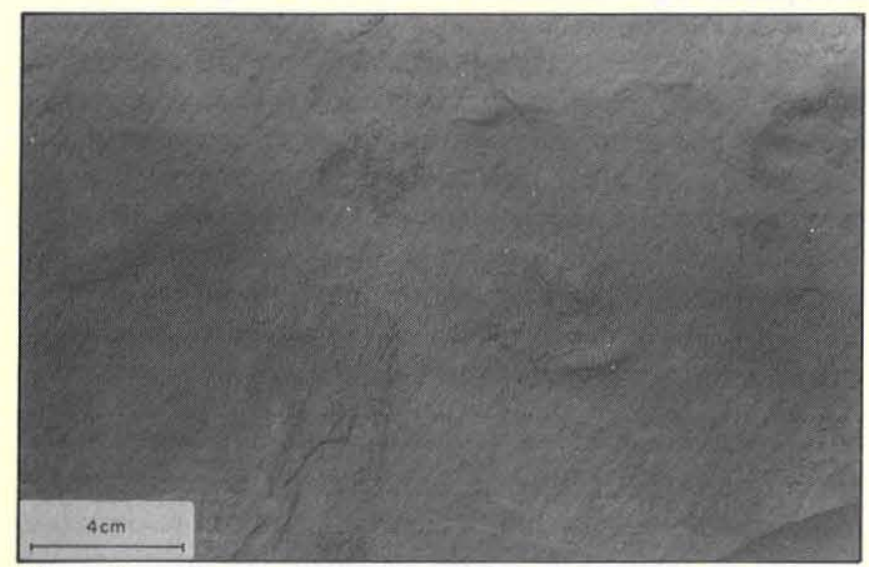

Foto 4 - Marcas rugosas (wrinkle marks) na superficie de um arenito fino, Formação Pedra de Fogo (? ). Alto Novo, rodovia $B R-316,74 \mathrm{~km}$ a $S$ de Teresina

\section{TIPOS DE MICROMARCAS ONDULADAS E TERMI-}

NOLOGIA As micromarcas onduladas descritas dos quatro afloramentos podem ser agrupadas de acordo com suas características em dois tipos distintos: a) marcas com cristas retilíneas e paralelas entre si; b) marcas com um padrão irregular ou pouco orientado de rugas.

As primeiras, que estão associadas a sedimentos da Formação Longá, correspondem às millimetre ripples de Singh \& Wunderlich (1978) ou linear small-scale ripple marks de Fouch \& Dean (1982). As últimas, encontradas em sedimentos das formações Piriá, Pimenteiras e Pedra de Fogo (?), são conhecidas na literatura como Krauselrippeln, curling ripples (Rücklin 1953), kinneyian ripples (Martinsson 1965) ou Runzelmarken, runzel marks, wrinkle marks (Hantzschel \& Reineck 1968, Reineck 1969, Teichert 1970).

0 termo kinneyian ripples foi utilizado por Martinsson, (1965): por ter essa marca certa semelhança com a "alga" kinneyia Walcott 1914 que Hantzschel (1962), no entanto, considerou como sendo uma estrutura abiótica. Prevalece na bibliografia o uso do termo wrinkle marks, embora devesse ser dada prioridade à denominação curling ripples, já que foi este o primeiro autor a reconhecer a origem dessa estrutura.
Propomos utilizar em português os termos ôndulas milimétricas para millimetro ripples e marcas rugosas para wrinkle marks ou Runzelmarken.

GÊNESE DE MICROMARCAS ONDULADAS Tanto as ôndulas milimétricas como as marcas rugosas formam-se em ambientes de água muito rasa, onde os sedimentos são sujeitos a emersão intermitente, como, por exemplo, nas planícies de maré, shoals, playas, margens de lagunas e lagos (Rücklin 1953, Reineck 1969, Singh \& Wunderlich 1978, Reineck \& Singh 1980, Fouch \& Dean 1982).

Nas planícies de maré do Mar do Norte (Alemanha), Reineck (1969) encontrou marcas rugosas na superfície daquelas areias finas sílticas que estavam emersas nos períodos de tempestade. No laboratório, simulando as condições naturais, o mesmo autor conseguiu reproduzir essa estrutura no topo de um sedimento fino, coeso, utilizando um jato de ar comprimido. As marcas rugosas formam-se não apenas em sedimentos finos expostos ao ar, mas também em depósitos cobertos por lâmina de água de até $1 \mathrm{~cm}$ de profundidade (Reineck 1969, Füchtbauer 1974).

Segundo Singh \& Wunderlich (1978), as ôndulas milimétricas diferem das marcas rugosas não só pela sua forma como também pelo modo de formação. Estes autores observaram em planícies de maré e shoals no Mar do Norte que ôndulas milimétricas eram originadas em areias finas e sedimentos siltosos, quando estes estavam cobertos por uma lâmina delgada de 1 a $3 \mathrm{~cm}$ de água e quando o vento produzia nela pequenas ondas internas que causavam o desenvolvimento de ôndulas milimétricas na superfície do sedimento. As cristas dessa estrutura foram freqüentemente aplainadas durante as fases de emersão. Essa característica foi observada claramente nas ôndulas milimétricas encontradas em síltitos de Formação Longá (Foto 3).

Pelo menos três fatores são importantes para a formação tanto das ôndulas milimétricas quanto das marcas rugosas: a granulometria fina do sedimento; uma velocidade relativamente alta do vento; e a emersão intermitente ou quase-emersão do sedimento.

Para que as micromarcas onduladas tenham boas chances de preservação, antes de soterramento, elas deveriam ser imediatamente cobertas de sedimentos finos de água calma após terem sido expostas ou quase expostas ao ar.

Todas estas condições, tanto para a formação quanto para a conservação das micromarcas onduladas, existem sobretudo nas planícies de maré (Ginsburg 1975, Klein 1977b, Reineck \& Singh 1980, Weimer et al. 1982), já que estas áreas de sedimentos predominantemente finos são alternativamente submersas pela preamar e expostas durante a baixamar. Durante a última fase, ventos fortes comuns nesse ambiente podem provocar a formação das micromarcas onduladas. Finalmente, as taxas elevadas de sedimentação, às quais estão geralmente sujeitas, permitem a preservação das marcas.

A importância do ambiente intermaré para a formação das micromarcas onduladas, particularmente das marcas rugosas, torna-se evidente sobretudo quando se registram os tipos de paleoambientes nos quais essas estruturas foram encontradas. Como está indicado na Tabela 1 , cerca de $70 \%$ das marcas rugosas têm sido observadas nas planícies de maré (tidal flats), desde o Pré-cambriano até o Recente. Seu registro em lagos ou lagunas é, aparentemente, menos fre- 
qüente. Embora esta compilação bibliográfica não pretenda ser completa, a ocorrência preferencial dessas estruturas nas planícies de maré está relacionada, possivelmente, também ao grande potencial de preservação de sedimentos intermarés no registro geológico (Klein 1977b) e à maior extensão, no passado, dos mares epicontinentais, nos quais formaram-se em proporções significativas (Klein 1977b) sedimentos clásticos cuja deposição é influenciadas pelas marés.

Tabela 1 - Distribuição temporal e ambiental de marcas rugosas (wrinkle marks) ${ }^{*}$. Presença de ôndulas milimétricas (millimetre ripples)

\begin{tabular}{|c|c|c|}
\hline AMBIENTE & IDADE & REFERENCLAS BIBLIOGRÁFICAS \\
\hline $\begin{array}{l}\text { Planície de maré, plataforma rasa } \\
\text { (tidal flat, shoal) }\end{array}$ & Recente & SINGH \& WUNDERLICH (1978) \\
\hline Planície de maré (tidal flat) & Recente & REINECK (1969) \\
\hline $\begin{array}{l}\text { Planície lacustre (lacustrine and } \\
\text { flat periodically exposed) }\end{array}$ & Eoceno Médio & FOUCH \& DEAN (1982) \\
\hline $\begin{array}{l}\text { Plataforma até antepraia (Offshore } \\
\text { to shoreface) }\end{array}$ & Jurássico Inferior & HANTZSCHEL \& REINECK (1968) \\
\hline $\begin{array}{l}\text { Laguna ou planície costeira (eva- } \\
\text { poritic lagoon or coastal flood } \\
\text { plain), areias costeiras, em parte } \\
\text { deltáicas (coastal sand fields, } \\
\text { deltaic in part) }\end{array}$ & Triássico Médio & SCHWARZ $(1970,1975)$ \\
\hline Planície de maré (tidal flat) & $\begin{array}{l}\text { Triássico Inferior/ } \\
\text { Médio }\end{array}$ & RUCKLIN (1953) \\
\hline Planície de maré (tidal flat) & Triássico Inferior & REIF \& SLATT (1979) \\
\hline Planície de maré (tidal flat) & Triássico Inferior & $\begin{array}{l}\text { KUMMEL \& TEICHERT (in) } \\
\text { TEICHERT, 1970) }\end{array}$ \\
\hline Playa & Permo-Triássico & DIJK VAN et al. (1978) \\
\hline Planície de maré (tidal flat) & $\begin{array}{l}\text { Devoniano Superior } \\
\text { e Carbonífero Inf. }\end{array}$ & $\operatorname{vos}(1977)$ \\
\hline $\begin{array}{l}\text { Planície de maré (channeled tidal } \\
\text { flat) }\end{array}$ & Devoniano & TANKARD \& BARWINS (1982) \\
\hline Planície de maré (tidal flat) & Devoniano Médio & MC CAVE (1973) \\
\hline $\begin{array}{l}\text { Ambiente de maré (tidal envi- } \\
\text { ronment) }\end{array}$ & Devoniano Inferior & WUNDERLICH (1970) \\
\hline Plataforma rasa (offshore shoal) & Siluriano Médio & HUNTER (1969) \\
\hline $\begin{array}{l}\text { Planície de maré (low-tidal sand. } \\
\text { flat) }\end{array}$ & Ordoviciano Inferior & TANKARD \& HOBDAY (1977) \\
\hline $\begin{array}{l}\text { Plataforma até antepraia (offshore } \\
\text { to shoreface) }\end{array}$ & Cambriano Médio & MARTINSSON (1965) \\
\hline $\begin{array}{l}\text { Praia (low energy, tide-dominated } \\
\text { beach) }\end{array}$ & $\begin{array}{l}\text { Proterozóico Supe- } \\
\text { rior até Cambriano } \\
\text { Inferior }\end{array}$ & AWASTHI \& PARKASH (1981) \\
\hline $\begin{array}{l}\text { Laguna ou lago (seasonal lagoon } \\
\text { or shallow lake edge) }\end{array}$ & Proterozóico & CLEMMEY (1978) \\
\hline $\begin{array}{l}\text { Laguna/zona intermaré (lagoonal } \\
\text { margin/intertidal zone) }\end{array}$ & Proterozóico & SINGH (1980) \\
\hline Planície ou maré (tidal flat) & $\begin{array}{l}\text { Proterozóico Supe- } \\
\text { rior }\end{array}$ & KLEIN (1975) \\
\hline Planície de maté (tidal flat) & Proterozóico Médio & VOS \& ERIKSSON (1977) \\
\hline Planície de maré (tidal flat) & Proterozóico Inferior & BEUKES (1977) \\
\hline $\begin{array}{l}\text { Planície de maré (lower interti- } \\
\text { sal sand flat) }\end{array}$ & Proterozóico Inferior & BUTTON \& VOS (1977) \\
\hline
\end{tabular}

\section{ESTRUTURAS SEMELHANTES ÀS MICROMARCAS ON-}

DULADAS Estruturas semelhantes às micromarcas onduladas, sobretudo às marcas rugosas, todavia de origem diferente, têm sido registradas em sedimentos de água profunda e, mais freqüentemente, em depósitos de água rasa ou de emersão.

Dzulynski \& Simpson (1966) descrevem patterns of wrinkles and ridges de arenitos finos terciários, de água profunda, do flysch polonês. Ao contrário das marcas rugosas, esta estrutura ocorre como marca basal em áreas extensas, variando em orientação e escala, e podendo ser associada a marcas de objetos (tool marks) e de escavação (scour markings). Os autores acima citados atribuem a formação deste padrão ao fluxo de turbidez exercendo força não erosiva de cisalhamento sobre uma superfície de sedimentos finos.

Outras estruturas que podem ser confundidas com as marcas rugosas são as marcas de espuma (foam marks,
Reineck \& Singh 1980), impressões de pingos de chuva desfigurados (Klein 1977b, rain-impact ripples, Clifton 1977) e ôndulas de adesão (adhesion ripples ou antiripplets, Reineck \& Singh 1980, Kocurek \& Fielder 1982, eolian microridges, Hunter 1969).

As marcas de espuma que comumente ocorrem em praias e planícies de maré, na interface água e sedimento coeso, são geradas pela sucção que a espuma provoca no sedimento, removendo pequenas quantidades de material e formando assim uma superfície rugosa. Este padrão, entretanto, geralmente em forma de pequenas cavidades semi-esféricas até elongadas, é mais irregular do que o das marcas rugosas (Reineck \& Singh 1980).

Pingos de chuva que caem sobre uma súperfície de sedimento coeso causam impressões circulares ou elípticas de acordo com o ângulo de queda dos pingos (Reineck \& Singh 1980). Segundo Klein (1977b), as impressões de pingos de chuva podem ser modificadas pela ação de ondas, resultando num padrão algo semelhante ao das marcas rugosas.

Klein (1977b) descreve tanto marcas de espuma quanto impressões desfiguradas de pingos de chuva sob o termo de marcas rugosas. Singh \& Wunderlich (1978) não concordam com isso por serem essas estruturas de origem diferente e defendem o uso mais restrito do termo marcas rugosas de acordo com o mecanismo gerador dessa micro-estrutura.

Ôndulas de adesão formam-se quando areia seca é transportada por saltação pelo vento sobre uma superfície molhada. Os grãos podem aderir à superfície do sedimento devido à força capilar da água, constituindo assim pequenas cristas que migram e crescem contra o sentido do vento (Reineck \& Singh 1980). Esta estrutura não é gerada quando uma delgada lâmina de água recobre a superfície do sedimento ou quando muita areia está sendo transportada. Embora as ôndulas de adesão mostrem, em alguns casos, semelhança com as marcas rugosas, estas últimas geralmente possuem no topo uma lâmina muito fina de argila. Esta não ocorre nas ôndulas de adesão que são originadas exclusivamente em material arenoso (Singh \& Wunderlich 1978).

Apesar das diferenças nos mecanismos genéticos, a zona de formação comum a essas últimas marcas é a superfície de emersão intermitente.

\section{A IMPORTÂNCIA DAS MICROMARCAS ONDULADAS NA ANÁLISE AMBIENTAL DOS SEDIMENTOS DAS FORMAÇÕES PIMENTEIRAS, LONGÁ, PEDRA DE FO-} GO (?) E PIRIÁ No capítulo "Gênese de micromarcas onduladas" foi mostrado que estas estruturas são preferencialmente ligadas às planícies de maré, sendo menos frequentemente encontradas em outros ambientes de água rasa.

Em seguida apresentamos sucintamente, com base em dados bibliográficos e trabalhos próprios, os paleoambientes geradores dos sedimentos Pimenteiras, Longá e Pedra de Fogo, na Bacia do Parnaíba, e Piriá, na região do Gurupi, com certa ênfase na presença possível de ambiente intermaré nestas formações.

Formação Pimenteiras A Formação Pimenteiras foi subdividida por Kegel (1953) nos membros Itaim e Picos. Aguiar (1971), entretanto, incluiu o Membro Inferior Itaim na Formação Serra Grande, restringindo a Formação Pimenteiras ao Membro Picos. Adota-se neste trabalho a definição dada por Aguiar (1971). 
Os sedimentos Pimenteiras, com ampla distribuição na região de Picos e caracterizados pela alternância de pelitos e psamitos, predominando os primeiros (Mesner \& Wooldridge 1964), depositaram-se em ambiente marinho muito raso, constituído por planícies e canais de maré, lagunas com pequena ação de correntes, cordões litorâneos e ilhas-barreira (Campanha \& Mabesoone 1974, Mabesoone 1977). Segundo Mabesoone (1977), a formação Pimenteiras mostra as feições mais típicas de planícies e canais de maré de todas as unidades estratigráficas na Bacia do Parnaíba.

As planícies são representadas por siltitos micáceos até folhelhos $\mathrm{e}$, às vezes, por arenitos de granulação fina. Estes arenitos apresentam laminação flaser e ondulada, além de bioturbações, enquanto os canais, de vários tamanhos, foram preenchidos por arenitos finos a médios, micáceos, mostrando raramente estratificação cruzada. Ocorrem nestes arenitos restos de plantas, braquiópodes e moluscos (Mabesoone 1977).

A presença de marcas rugosas em siltitos da parte inferior do perfil de Picos corrobora, sem dúvida, a interpretação ambiental acima apresentada, atribuindo às planícies de maré um papel importante durante a deposição dos Sedimentos Pimenteiras.

Formação Longá Semelhante à Formação Pimenteiras, a Formação Longá, constituída principalmente de pelitos, é indicativa de um ambiente marinho raso, em grande parte litorâneo (Mesner \& Wooldridge 1964). Esta interpretação baseia-se sobretudo na presença de abundantes tubos de vermes, marcas onduladas e camadas finas de folhelhos e siltitos. Muniz (1982), com base no estudo de ichnofósseis, sugere um ambiente infralitoral e circalitoral (offshore) para a Formação Longá. Todavia, o mesmo autor descreve algumas ichnospécies da região de Campo Maior (PI) que permitem também interpretar uma parte da seqüência como depositada em águas marinhas mais rasas. Segundo Mabesoone (1977), os sedimentos Longá testemunham um ambiente angular, com circulação restrita da água, possivelmente sujeito às influências de maré (tidal lagoon). Mabesoone (1977) cita gretas de contração em pelitos, o que sugere exposição subaérea para uma parte dos Sedimentos Longá.

As ôndulas milimétricas encontradas em siltitos de Campo Maior confirmam esta interpretação. Por conseguinte, é provável que o subambiente de planície de maré faça parte do sistema deposicional da Formação Longá (Carozzi et al. 1974).

Formação Pedra de Fogo(?) O pequeno afloramento entre Monsenhor Gil e Barro Duro, a S de Teresina, no qual as marcas rugosas da Foto 4 foram registradas, pertence, como já assinalado, ou à Formação Pedra de Fogo ou à Formação Motuca. Qualquer que seja a formação, as fáceis de ambas as unidades indicam comumente condições deposicionais de água muito rasa. Foram reconhecidos nessas duas formações os ambientes marinho (regressivo), lacustre (playa), fluvial e desértico, com transições entre elas (Mesner \& Wooldridge 1964, Mabesoone 1977). Segundo Della Favera (1980) e Faria Jr \& Truckenbrodt (1980), sedimentos de planície de maré ocorrem na Formação Pedra de Fogo.

Formação Piriá Poucas informações estratigráficas e ambientais existem sobre a Formação Piriá (denominação de Costa et al. 1977), que aflora entre Santa Luzia e o Rio Gurupi, na região NE do Estado do Pará. Possivelmente de idade eopaleozóica(Costa et al. 1975, Abreu et al. 1980), os Sedimentos Piriá, constituídos de pelitos e arenitos (predominantemente subarcóseos e arcóseos de granulação fina e grosseira) intercalados, foram depositados em ambiente marinho, talvez na zona epinerítica, como sugerem Molnar \& Urdininea (1966). A predominância de clásticos finos, bem laminados, e a presença de grãos bem arredondados nos arenitos arcoseanos, assim como das marcas onduladas, da estratificação lenticular e das estruturas de bioturbação, corroboram esta interpretação, embora possam indicar condições deposicionais ainda mais rasas. Até agora os dados de campo não foram suficientes para detalhar melhor o ambiente marinho. $\mathrm{O}$ forte grau de intemperismo dos sedimentos e a escassez de bons afloramentos dificultam uma análise mais pormenorizada do sistema deposicional da Formação Piriá. Propõe-se, por enquanto, como hipótese de trabalho, o ambiente intermaré (planície de maré) para a deposição de, pelo menos, uma parte dos sedimentos Piriá, tendo em vista a importância das marcas rugosas e das poucas estruturas sedimentares observadas. Outras investigações serão necessárias para testar esta proposta ambiental.

CONCLUSÕES Marcas rugosas e ôndulas milimétricas formam-se em sedimentos de granulação fina (silte, areia fina), quando estes estão recobertos por uma lâmina delgada de água ou expostos ao ar e afetados por ventos fortes. segundo Singh \& Wunderlich (1978), ôndulas milimétricas poderiam ser geradas também sob condições particulares, em águas mais profundas. Esses autores relatam, entretanto, que até hoje tais estruturas não têm sido observadas em zonas profundas, e que em sedimentos antigos também as ôndulas milimétricas têm sido encontradas sempre associadas a tais estruturas, que indicam emersão ou quase emersão dos sedimentos.

Marcas semelhantes às rugosas e, como essas, geradas na interface água/ar são as marcas de espuma, impressões de pingos de chuvas desfiguradas pela ação de ondas e ôndulas de adesão levemente modificadas pela água. Apesar das origens diferentes destas estruturas, o pré-requisito comum para sua formação é a exposição intermitente dos sedimentos (Klein 1977b).

Entre os ambientes deposicionais geradores tanto das ôndulas milimétricas como das marcas rugosas destaca-se o de planície de maré. Um estudo bibliográfico mostrou que cerca de $70 \%$ dessas estruturas foram registradas nesse ambiente, o qual apresenta características dinâmicas e granulométricas particularmente propícias para a geração das micromarcas onduladas, além de ser favorável para sua preservação.

As micromarcas onduladas, junto com outros dados paleoambientais evidenciados nas formações Pimenteiras e Longá, sugerem que a fase talassocrática, abrangendo o primeiro ciclo sedimental (Ordoviciano/Siluriano até Carbonífero Inferior) da história da Bacia do Parnaíba (Mesner \& Wooldridge 1964), foi caracterizada por processos deposicionais de maré. A Formação Pimenteiras (Devoniano Médio e Superior) apresenta as feições mais típicas de planície e canais de maré (Mabesoone 1977). 0 último episódio marinho (regressivo) na Bacia do Parnaíba marcado pela in- 
fluência das marés ocorreu, provavelmente, durante o período Pedra de Fogo, no Permiano (Della Favera 1980). As marcas rugosas encontradas ao sul de Teresina, em arenitos finos, parecem confirmar a hipótese. Após o recuo do mar, iniciado no Carbonífero e acentuado durante o Permiano, estabeleceu-se definitivamente a fase geocrática do segundo ciclo sedimentar (Carbonífero Superior até Jurássico) da história da Bacia do Parnaíba (Mesner \& Wooldridge 1964).

Propõe-se igualmente o ambiente intermaré, como hipótese de trabalho, para os sedimentos da Formação Piriá aflorantes na região do Gurupi.

Embora as marcas rugosas e a ôndulas milimétricas sejam consideradas como estruturas importantes do ambiente intermaré, elas, por si só, não são suficientes para definir essa zona deposicional. É o conjunto de estruturas sedimentares observáveis na seqüência litológica vertical que permite a definição do ambiente deposicional (Shawa 1979). Neste sentido, Klein (1977b) apresenta dez associações distintas de estruturas e características texturais relacionadas a processos deposicionais de maré, para o reconhecimento dos ambientes intermaré e inframaré raso.

Agradecimentos $\mathrm{O}$ autor agradece ao $\mathrm{CNPq}$ pelo apoio financeiro. Agradecimentos são devidos também a Ana Maria Góes pela cessão da amostra oriunda da Formação Pimenteiras; a Basile Kotschoubey e a Marcondes Lima da Costa; e ao Corpo Consultivo da RBG, pelas sugestões que contribuíram para a melhoria deste artigo.

\section{REFERÊNCIAS BIBLIOGRÁFICAS}

ABREU, F.A.M.; VILLAS, R.N.N.; HASUI, Y. - 1980 - Esboço estratigráfico do Pré-Cambriano da região do Gurupi, estados do Pará e Maranhão. In: CONGR. BRAS. GEOL., 31, Camboriú, 1980, Anais... Camboriú, SBG, v. 2, p. 647-658.

AGUIAR, G.A. - 1971 - Revisão geológica da Bacia Paleozóica do Maranhão. In: CONGR. BRAS. GEOL., 25, São Paulo, 1971. Anais... São Paulo, SBG, v. 3, p. 113-122.

ALLEN, J.R.L. - 1968 - Current ripples. Their relation to patterns of water and sediment motion. Amsterdã, North-Holland Pibl. Comp. 433 p.

AWASTHI, A.K. \& PARKASH, B. - 1981 - Depositional enviroments of unfossiliferous sediments of the Jodhpur Group, wastern India. Sediment. Geol., 30: 15-42.

BEUKES, N.J. - 1977 - Transition from siliciclastic to carbonate sedimentation near the base of the Transvaal Supergroup, northern Cape Province. South Africa. Sediment Geol., 18: 201-221.

BUTTON, A. \& VOS, G.R. - 1977 - Subtidal and intertidal clastic and carbonate sedimentation in a macrotidal environment: an example from the Lower Proterozoic of South Africa. Sediment Geol., 18: 171-200.

CAMPANHA, V.A.; MABESOONE, J.M. - 1974 - Paleozmbiente e paleoecologia do Membro Picos, Formação Pimenteiras (Devoniano do Piauí). In: CONGR. BRAS, GEOL., 28, Porto Alegre, 1984. Anais... Porto Alegre, SBG, v. 2, p. 221-235.

CAROZZI, A.V.; FALKENHEIN, F.U.H.; CARNEIRO, R.G.; ESTEVES, R.F.; CONTREIRAS, C.J.A. - 1974 - Análise ambiental e evolução tectônica sinsedimentar da seção siluro-eocarbonifera da Bacia do Maranhão. Rio de Janeiro, Petrobrás/Cenpes. 48 p. (Ciência-Técnica-Petróleo, Seção Expl. Petróleo,

CLEMMEY, H. - 1978 - A proterozoic lacustrine interlude from the Zambian copperbelt. In: MATTER, A; TUCCKER, M. E. eds. Modern and ancient lake sediments. Oxford, International Assoc. Sedimentologists, p. 259-278 (special publication 2).

CLIFTON, H.E. - 1977 - Rain-impact ripples. Jour Sed. Petrol., 47: 678-679.

COSTA, J.L.; ARAUJO, A.A.F.; VILLAS BOAS, J.M.; FARIA, C.A.S.; NETO, C.S.S.; WANDERLEY, V.J.R. - 1977 - Projeto Gurupi, Belém, DNPM/CPRM. v. 1, 258 p. (relatório final).

COSTA, J.L.; VILLAS BOAS, J.M.; PASTANA, J.M.N.; WANDERLEY, V.J.R.; ARAUJO, A.A.F.; FRIZZO, S.J. - 1975 - Projeto Gurupi. Belém, DNPM/CPRM, v. 1, 251 p. (relatório preliminar).

DELLA FAVERA, J.C. - 1980 - Reconhecimento de novas facies e ambientes deposicionais na Bacia do Parnaíba, In: CONGR. BRAS. GEOL., 31, Camboriú, 1980. Res. Com.... Camboriú, SBG, Bol. 2, p. 357.

DIJK VAN, D.E.; HOBDAY, D.K.; TANKARD, A.J, - 1978 - Permo-Triassic lacustrine deposits in the eastern Karoo Basin, South Africa. In: MATTER, A. \& TUCKER, M.E. eds. Modern and ancient lake sediments. Oxford, International Assoc. Sedimentologists, p. 225-239. (special publication 2).
DZULYNSKI, S. \& SIMPSON, F. - 1966 - Experiments on interfacial current markings. Geol, Romana, 5: 179-214.

FARIA JR., L.E. \& TRUCKENBRODT, W. - 1980 - Estromatólitos na Formação Pedra de Fogo, Permiano, Bacia do Maranhão. In: CONGR. BRAS. GEOL., 31, Camboriú, 1980. Anais... Camboriú, SBG, v. 5, p. 3056-3067.

FOUCH, T.D. \& DEAN, W.E. - 1982 - Lacustrine and associated clastic depositional environments, In: SCHOLLE, P. A. \& SPEARING, D. eds. Sandstone depositional enviroments. Tulsa, AAPG, p. 87-114 (Memoir 31).

FUCHTBAUER, H. - 1974 - Sediments and sedimentary rocks. Stuttgart, Scheiwaeizerbart. 464 p.

GINBURG, R.N. ed. - 1975 - Tidal deposits. New York, Springer. $428 \mathrm{p}$.

HANTZSCHEL, W. \& REINECK, H.E. - 1968 - Fazies - UntersuchunMOORE, R. C. ed. Treatise on invertebrate paleontology. Lawrence Univ. Kansas Press, v. W, p. W117-W245.

HANTZSCHEL, W. REINECK, H.E. - 1968 - Fazies- Untersuchungen in Hettangium von Helmstedt (Niedersachsen). Mitt. Geol. Staatsinst. Hamburgo, 37: 5-39.

HARMS, J.S.; SOUTHARD, J.B.; WALKER, R.G. - 1982 - Structures and sequences in clastic rocks. Tulsa, Soc. Econ. Paleont. Mineralogists. (Short course 9).

HASUI, Y.; ABREU, F.A.M.; VILLAR, R.N.N. - 1984 - Província Parnaíba. In: ALMEIDA, F.F.M. \& HASUI, Y. coords. O PréCambriano do Brasil, São Paulo, E. Blücher, p. 36-45.

HUNTER, R.E. - 1969 - Eolian microridges on modern beaches and a possible ancient example. Jour. Sed. Petrol., 39:1573-1578.

KEGEL, W. - 1953 - Contribuição para o estudo do Devoniano da Bacia do Parnatba. Rio de Janeiro, DNPM/DGM, 48 p. (Boletim 141).

KLEIN, G. DE V. - 1975 - Paleotidal range sequences, Middle Member, Wood Canyon Formation (Late Precambrian), Eartern California and Western Nevada. In: GINSBURG, R. ed. Tidal deposits. Berlin, Springer, p. 171-177.

KLEIN, G. DE V. - 1977a - Tidal circulation model for deposition of clastic sediment in epeiric and mioclinal shelf seas. Sediment. Geol., 18: 1-12.

KLEIN, G. DE V. - 1977b - Clastic tidal facies. Campaign, Cepco, $149 \mathrm{p}$.

KOCUREK, G. \& FIELDER, G. - 1982 - Adhesion structures. Jour. Sed. Petrol, 52:1229-1241.

MABESOONE, J.M. - 1977 - Paleozoic-Mesozoic deposits of the Piauí-Maranhão Syneclise (Brazil): geological history of a sedimentary basin. Sediment. Geol., 19: 7-38.

MARTINSSON, A. - 1965 - Aspects of a Middle Cambrian thanatotoque on Oland. Geol. Foren. Stockholm Forh., 87: 181-230.

MC CAVE, J. N. - 1973 - The sedimentology of a transgression: Portland Point and Cooksburg Members (Middle Devonian), New York State. Jour. Sed. Petrol., 43: 484-504.

MESNER, J.C. \& WOOLDRIDGE, L.C.P. - 1964 - Maranhão Paleozoic Basin and Cretaceous coastal basins, north Brazil. Bull. 
Amer. Ass. Petr. Geol, , 48: 1475-1512.

MOLNAR, A.B. \& URDININEA, J.S.A. - 1966 - Reconhecimento geológico entre as bacias do Amazonas e Maranhão. Rio de Janeiro, Petrobrás/Renor, 56 p. (relatório interno, 50 G).

MUNIZ, G. C. B. - 1982 - Ichnofósseis devonianos da Formação Longá, no Estado do Piauí. In: CONGR. BRAS. GEOL., 32, Salvador, 1982. Anais... Salvador, SBG, v. 4, p. 1305-1316.

REIF, D.M. \& SLATT, R.M. - 1979 - Red bed members of the Lower Triassic Moenkoepi Formation, southern Nevada: sedimentology and paleogeography of a muddy tidal flat deposit. Jour Sed Petrol., 49: 869-890.

REINECK, H. - 1969 - Die Entstehung con Runzelmarken. Natur and Museum, 99: 386-388.

REINECK, H.E. \& SINGH, I.B. - 1980 - Depositional sedimentary enviroments. 2a. ed. Berlin, Springer, 549 p.

RUCKLIN, H. - 1953 - Die Grenzschichten Buntsandstein/Muschelkalk im Searland - ein fossiler Watt. Jber. u. Mitt. Oberrh. Geol. Ver. N. F., 35: 26-42.

SARKAR, S. - 1981 - Ripple marks in intertidal Lower Bhander Sandstone (Late Proterozoic), Central India: a morphological analysis. Sediment. Geol., 29: 241-282.

SCHWARZ, H.U. - 1970 - Zur Sedimentologie und Fazies des Unteren Muscheilkalkes in Südwestdeuschland und angrenzenden Gebieten. (Diss.). Tübingen, Univ. - Tübingen, 297 p.

SCHWARZ, H.U. - 1975 - Sedimentary structures and facies analysis of shallow marine carbonates. Stuttgart, Schweizerbart, $100 \mathrm{p}$. (Contr. Sedimentology, 3).

SHAWA, M.S. ed. - 1979 - Use of desimentary structures for recognition of clastic environments. 2a ed. Calgary, Canadian Soc. Petroleum Geologists, $66 \mathrm{p}$.

SINGH, I.B. - 1980 - The Bijaigarh shale, Vindhyan System (Precambrian), India - an example of a lagoonal deposit. Sediment. Geol., 25: 83-103.
SINGH, I.B. \& WUNDERLICH, F. - 1978 - On the terms wrinkle marks (Runzelmarken), millimetre ripples, and mini ripples. Senckenbergiana marit., 10: 75-83.

TANKARD, A.J. \& BARWIS, J.H. - 1982 - Wave-dominated deltaic sedimentation in the Devonian Bokkeveld Basin of South Africa. Jour. Sed. Petrol., 52: 959-974.

TANKARD, A.J. \& HOBDAY, D.K. - 1977 - Tide dominated back-barrier sedimentation, Early Ordovician Cape Peninsula, South Africa. Sediment. Geol., 28: 135-159.

TANNER, W.F. - 1967 - Ripple mark indices and their uses. Sedimentology, 9: 89-104.

TEICHERT, C. - 1970 - Runzelmarken (wrinkle marks). Jour. Sed. Petrol. 40: 1056-1057.

VOS, R.G. - 1977 - Sedimentology of an Upper Paleozoic river, wave and tidal influenced delta system in southern Morocco. Jour. Sed. Petrol., 47: 1242-1260.

VOS, R.G. \& ERIKSSON, K.A. - 1977 - An ambayment model for tidal and wave swash deposits occuring within a fluvially dominated Middle Proterozoic sequence in South Africa. Sediment. Geol., 18: 161-173.

WEIMER, R.J.; HOWARD,; LINDSAY, D.R. - 1982 - Tidal flats and associated tidal channles. In: SCHOLLE, P. A. \& SPEARLING, D. eds., Sandstone depositional environments. Tulsa, AAPG, p. 191-245 (Memoir 31).

WUNDERLICH, F. - 1970 - Genesis and environment of the "Nellenkopfchenschichten" (Lower Emsian, Rheinian Devon) at locus typicus in comparison with modern coastal environment of the German Bay. Jour. Sed. Petrol., 30:102-130.

MANUSCRITO

Recebido em 18 de janeiro de 1985 Revisão aceita em 12 de junho de 1985

Quando a história geológica de uma área foi determinada, é freqüentemente possível, em retrospectiva, encontrar um único espécime mesoscópico ou afloramento que demonstrem a sua história deformacional.

Paul F. Williams, J. Struct. Geol., 7 (3/4), p. 269. 